\title{
LEIOMIOSSARCOMA DE JEJUNO
}

\author{
JEJUNUM'S LEIOMYOSARCOMA
}

\author{
Nilton Ghiotti de Siqueira, TCBC-AC ${ }^{1}$ \\ Cláudia Maria Villar Maziero de Siqueira ${ }^{2}$
}

\section{INTRODUÇÃO}

Massas abdominais são um desafio diagnóstico.

Tumores malignos de intestino delgado representam de $0,2 \%$ a $2 \%$ das neoplasias malignas do trato gastrintestinal, e devemos tê-las em mente, pois a possibilidade de cura, está diretamente relacionada com a precocidade do diagnóstico ${ }^{1,2}$.

Apresentamos um caso de leiomiossarcoma de jejuno, o qual a tomografia computadorizada (TC) do abdome demonstrava imagem curiosa e atípica.

\section{RELATO DO CASO}

A.P.L., masculino, 56 anos, apresentava dor abdominal vaga com evolução de quatro anos. Há um ano notou massa mesogástrica e há seis meses, apresentou episódios de diarréia (melena?). Negava antecedentes cirúrgicos. Encontrava-se emagrecido com massa palpável em mesogástrio de $15 \mathrm{~cm}$ de diâmetro, indolor, fixa, endurecida. O raios $\mathrm{X}$ simples do abdome nada esclareceu e a TC demonstrava: massa isodensa de $10 \mathrm{~cm}$, em flanco direito, englobando alças de delgado e aderida ao cólon ascendente e em seu interior há artefato metálico (Figura 1A e B).

Submetido à laparotomia em 17 de março de 1998, tratava-se de um tumor a $40 \mathrm{~cm}$ do ângulo de Treitz, crescendo em sentido mesentérico, preservando a borda antimesentérica, aderido ao mesocólon ascendente. Excisouse a lesão em bloco (cólon direito e o segmento jejunal acometido), com margem de segurança de $15 \mathrm{~cm}$ distal e proximal ao tumor. A reconstituição foi com enteroenteroanastomose e ileotransversostomia. Aberta a peça cirúrgica, evidenciado pequeno fragmento metálico. Alta hospitalar no oitavo dia, sem intercorrências. A histopatologia revelou tratar-se de leiomiossarcoma bem diferenciado, com 10 mitoses/10 campos de grande aumento, sem infiltração vascular e linfonodos sem metástases. Na revisão, aos cinco meses, o paciente encontrava-se assintomático.

\section{DISCUSSÃO}

Os leiomiossarcomas do intestino delgado são mais freqüentes em homens (1.30:1.00) entre a quarta e sexta décadas ${ }^{1,3,4}$.Originam-se da musculatura lisa e crescem para

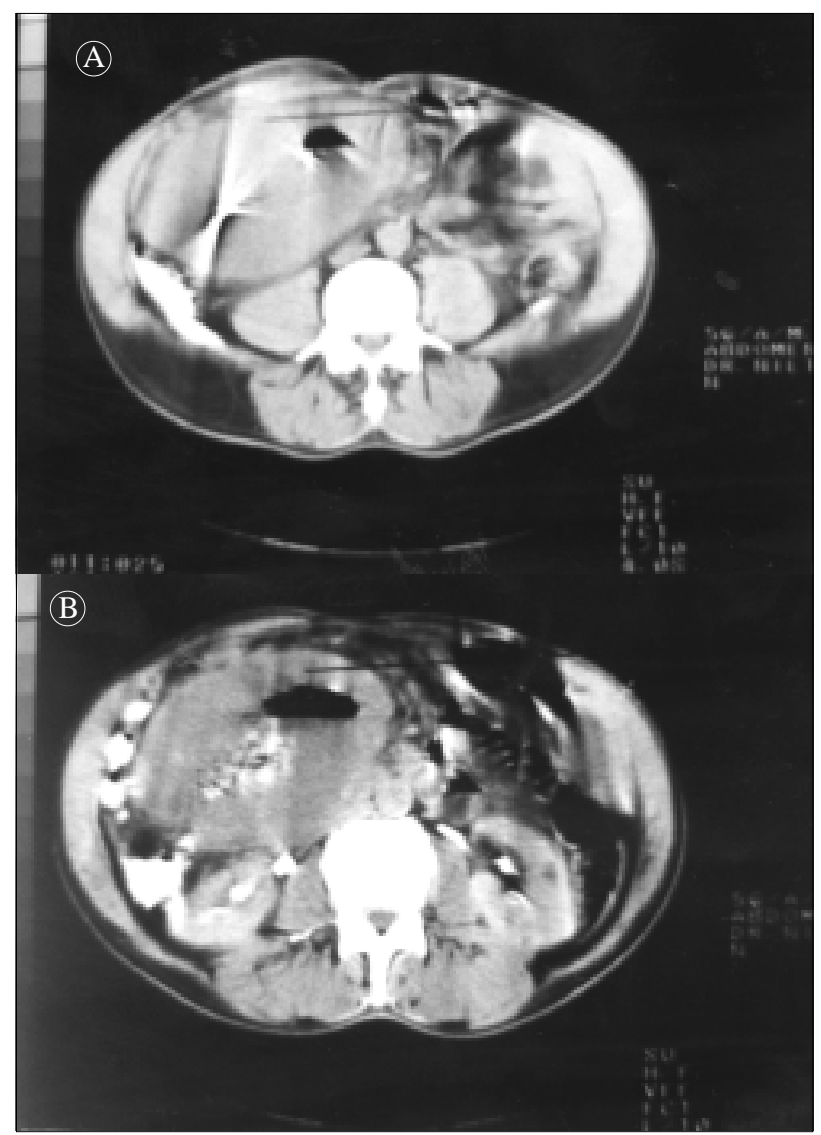

Figura 1 - Aspecto tomográfico do tumor. À) nota-se fragmento metálico no interior da massa (artefato); B) luz intestinal comunicando-se com a cavitação do tumor.

1. Cirurgião Geral da Fundação Hospital Estadual do Acre.

2. Radiologista da Fundação Hospital Estadual do Acre.

Recebido em 4/6/1999

Aceito para publicação em 28/7/2000

Trabalho realizado na Fundação Hospital Estadual do Acre 
o lúmem intestinal em sentido extraparietal (a forma mais comum) ou ambos ${ }^{3,4}$. A dor abdominal e a perda de peso são os sintomas mais freqüentes e a dor pode ser devida à obstrução intermitente, intussuscepção ou perfuração para peritônio livre ${ }^{2}$. Ricamente vascularizados, sangram facilmente e quando atingem grandes dimensões apresentam necrose central e perfuram para o mesentério, formando "cistos", ou para o peritônio livre ${ }^{3}$. Massas abdominais palpáveis estão presentes em grande parte dos casos ${ }^{4}$. O raios X simples pode revelar sinais compatíveis com obstrução intestinal, pequenas calcificações e/ou imagem sugestiva de abscesso ${ }^{3,5}$. O trânsito de delgado pode evidenciar sinais indiretos do tumor como: distensão abdominal a montante da lesão, alterações da peristalse, ulceração, compressão extrínseca ou paresia do segmento acometido com alterações de mucoas ${ }^{3,5}$. A angiografia abdominal é excelente meio auxiliar tanto do diagnóstico quanto para localização do tumor enquanto a TC é o meio de maior sensibilidade diagnóstica (98\%) e propicia boa avaliação tática pré-operatória, além de detectar metástases que podem ser disseminadas via hematogênica, implantação pe- ritoneal, invasão local ou mais raramente por via linfática sendo diretamente relacionadas com o diâmetro do tumor (maiores que $9 \mathrm{~cm}$ de diâmetro) ${ }^{3,4}$. Existem relatos de associação entre leiomiossarcoma e outros tumores primários, sugerindo fatores sistêmicos na gênese da doença, bem como a concomitância de úlceras duodenais, doença de Crohn, polipose intestinal, doença de Von Recklinghausen e doença celíaca ${ }^{3}$. O tratamento é cirúrgico, a radioterapia não é eficaz e a quimioterapia questionável ${ }^{3,4}$. Parece haver melhor prognóstico em pacientes com duração dos sintomas menor que um ano e tumores de tamanho menor que nove centímetros ${ }^{1,3}$. No caso relatado, o diagnóstico foi histológico. Não dispomos de biópsia de congelação e o artefato presente na TC, nos fez tecer outras considerações, suscitando a possibilidade de doença benigna (granuloma de corpo estranho, visto que o paciente possui "casa de farinha", com tachos freqüentemente enferrujados que desprendem fragmentos) corroborando a forma cística que a doença assumiu. Durante a laparotomia, optamos por uma ressecção ampla, assegurando assim um tratamento adequado para a lesão.

\begin{abstract}
We describe a case of leiomyosarcoma of the jejunum in which abdominal computed tomography showed an intestinal tumor with a "sui generis" metalic artefact inside, which made us think of a benign disease (foreign body granuloma), because the patient lived in the rural area and he had a manioc flour mill, which is one the basic foods of the majority of the population of the north in Brazil. Because of the aspect of the tumor, we decided on a large scale resection, considering the possibility of a malignant tumor since we don't have frozen sections. This assured us of an adequate treatment for the tumor. This type of pathology should be remembered even though it only accounts for 0,2-2\% of the intestinal tract tumors.
\end{abstract}

Key Words: Leiomyosarcomas; Small Bowel Tumors.

\title{
REFERÊNCIAS
}

1. Chiotasso PJP , Fazio V W : Prognostic factors of 28 Leiomyosarcomas of the Small Intestine. Surg. Gynecol. Obstet. 155(2) : 197-202, 1982 Aug.

2. North JH, Pack MS: Malignant Tumors of the Small Intestine: A Review of the 144 cases. Am. Surg. 66(1): 4651, 2000 Jan.

3. Di Vita G, Mezzatesta N, Asaro M, Carpino S : I Leiomiosarcomi Dellintestino Tenue. Minerva Chir. 45 (7) : 455-60, 1990 Apr 15.

4. Blanchard DK, Budde JM, Hatch GF $3^{\text {rd }}$, et al: Tumors of the Small Intestine. World J. Surg. 24(4): 421-9, 2000 Apr.
5. Bucley JA, Fishman EK : CT Evaluation of Small Bowel Neoplasms : Spectrum of Disease . RadioGraphics 18(2):379-392, 1998 Mar/Apr.

Endereço para correspondência:

Dr. Nilton Ghiotti Siqueira

Rua Siqueira Campos, 77

69914-510 — Rio Branco-AC

E-mail: ghiotti@mdnet.com.br 